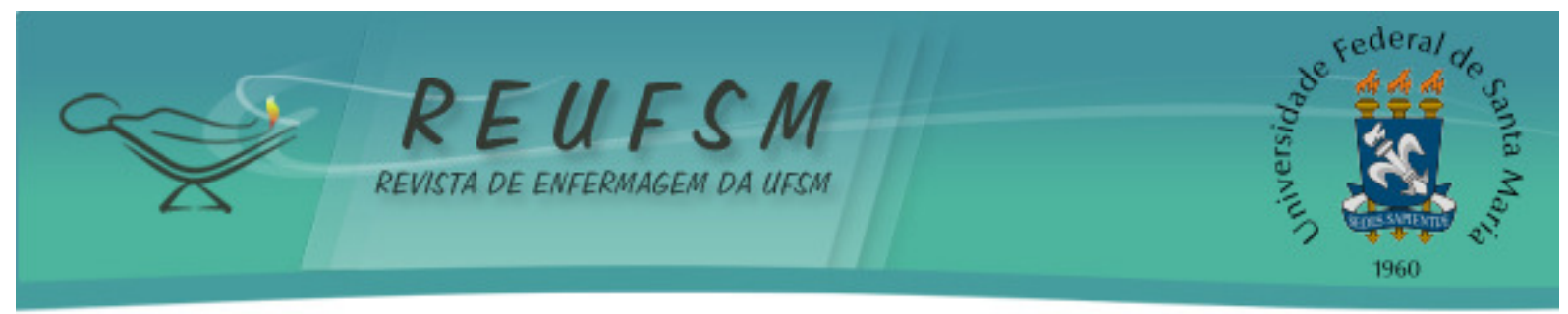

ARTIGO ORIGINAL

\title{
CONTENÇÃO DA VIOLÊNCIA ESCOLAR SOB A ÓTICA DOS FUNCIONÁRIOS DE UMA ESCOLA PÚBLICA
}

\section{RETENTION OF SCHOOL VIOLENCE UNDER THE PERSPECTIVE OF A PUBLIC SCHOOL EMPLOYEES}

\section{CONTENCIÓN DE LA VIOLENCIA ESCOLAR A TRAVÉS DE LA PERSPECTIVA DE LOS EMPLEADOS DE UNA ESCUELA PÚBLICA}

\author{
Luciana Netto ${ }^{1}$ \\ Rayssa Nogueira Rodrigues ${ }^{2}$ \\ Mariana Aparecida Costa ${ }^{3}$ \\ Jaqueline dos Santos ${ }^{4}$ \\ Gabriel Alves Tatagiba ${ }^{5}$
}

RESUMO: Objetivo: conhecer as estratégias de contenção da violência escolar na visão de funcionários de uma escola estadual do município de Divinópolis-MG. Método: trata-se de estudo descritivo, qualitativo. Os dados foram coletados através de entrevistas e posteriormente transcritos, avaliados por meio da análise de conteúdo. Resultados: a partir de discursos repetidos duas categorias foram organizadas: 0 papel da escola e 0 papel da família. Corroborada a situação multiproblemática, os entrevistados não dispuseram de medidas que os articulem na capacitação requerida aos professores. Conclusão: constata-se que os entrevistados possuem conhecimento de um número maior de situações de conflito entre professor-aluno, o que faz desses depoimentos condizentes com a real necessidade daquele ambiente. Ressalta-se ainda, a premência de integrar ações com estratégias que envolvam os funcionários na formação e capacitação requerida aos professores.

Descritores: Enfermagem; Violência; Saúde escolar; Recursos humanos.

ABSTRACT: Aim: to identify strategies to curb school violence in vision by employees in a public school in the city of Divinópolis-MG. Methods: this is a descriptive and qualitative study. Data were collected through interviews and later transcribed, evaluated by means of content analysis. Results: from repeated speeches were organized two categories: The role of schools and the role of the family. Corroborated the of multiple problems situation, the respondents not told with measures that articulate the training required for teachers. Conclusion: it appears that the respondents have knowledge of a larger number of situations of conflict between teacher and student, which makes these statements consistent with the actual need of that environment. We also emphasize the urgent need to integrate actions with strategies to involve employees in the education and training required for teachers.

Descriptors: Nursing; Violence; School health; Human Resources.

\footnotetext{
${ }^{1}$ Enfermeira. Doutoranda em Enfermagem pela Universidade Federal de Minas Gerais. Professora Assistente II da Universidade Federal de São João Del-Rei. São João Del-Rei, MG, Brasil. E-mail: luciananetto@ufsj.edu.br ${ }^{2}$ Graduanda em Enfermagem pela Universidade Federal de São João Del Rei. São João Del-Rei, MG, Brasil. Email: rayssa_nr@yahoo.com.br

${ }^{3}$ Graduanda em Enfermagem pela Universidade Federal de São João Del Rei. PIIC (FAPEMIG/UFSJ). São João Del-Rei, MG, Brasil.

maricosta.ufsj@yahoo.com.br

${ }^{4}$ Discente do Ensino Médio. Bolsista da FAPEMIG - PIBIC Júnior. São João Del-Rei, MG, Brasil. E-mail: jakel08@hotmail.com

${ }^{5}$ Discente do Ensino Médio. Bolsista da FAPEMIG - PIBIC Júnior. São João Del-Rei, MG, Brasil. E-mail: gabrieltatagiba99@yahoo.com.br
} 


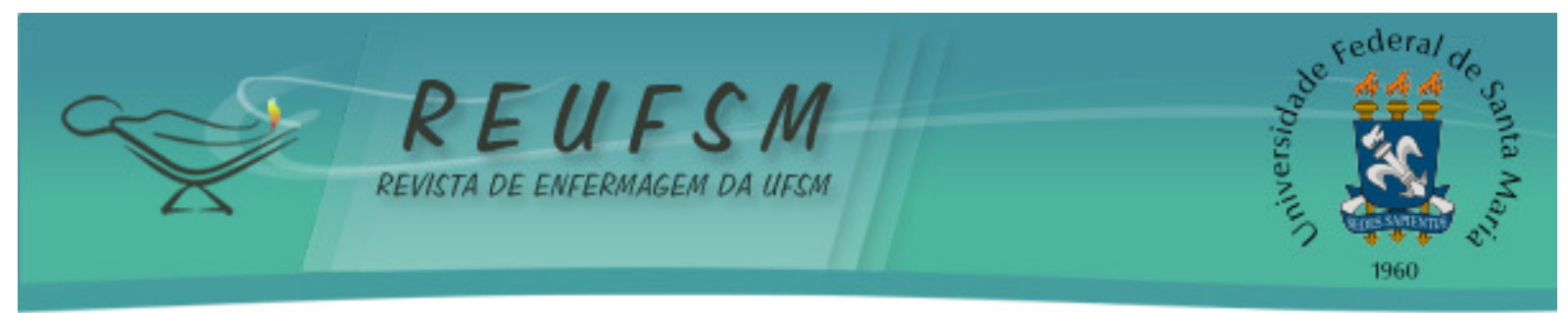

RESUMEN: Objetivo: conocer las estrategias de contención de la violencia escolar en la visión de los empleados en una escuela pública en la ciudad de Divinópolis-MG. Metodología: estudio descriptivo, cualitativo. Los datos fueron recolectados a través de entrevistas y posteriormente transcritas, evaluados por medio de análisis de contenido. Resultados: a partir de discursos repetidos dos categorías fueron organizadas: el papel de la escuela y el papel de la familia. Así, confirmada la situación multiproblemática, los encuestados no dispusieron de medidas que los articulen en formación requerida a los profesores. Conclusión: se verifica que los encuestados conocen más conflicto entre profesor y estudiante, lo que hace estas declaraciones en consonancia con la necesidad real de ese entorno. También se resalta la urgente necesidad de integrar las acciones con las estrategias para involucrar a los empleados en la educación y la formación necesaria para los profesores.

Descriptores: Enfermería; Violencia; Salud escolar; Recursos humanos.

\section{INTRODUÇÃO}

Na sociedade contemporânea, a violência replica-se tão permanente e provável em um contexto que se abandona a percepção de um acontecimento inusitado. Apreendida por sua presença generalizada, a sociedade tem sido levada a incorporar a violência como um componente imanente à atualidade. ${ }^{1}$

Esse panorama gera como consequência a diminuição da esperança em relação à provável compreensão e enfrentamento das causas de sua ampliação, estreitando o foco do impasse ao âmbito limitado das políticas que a coíbem e controlam. ${ }^{2} \mathrm{E}$ é nesse cenário que o Brasil vem enfrentando as diversas formas de violência perpetradas contra crianças e adolescentes. Opor-se à teia de violência que por vezes inicia no ambiente doméstico ou em locais que deveriam amparar, preservar e tutelar as pessoas configura-se em um difícil problema a ser solucionado. ${ }^{3}$

Nas últimas décadas, as escolas têm apresentado cada vez mais queixas com relação às condutas apresentadas pelos alunos, sendo as mais comuns: a atitude de afronta; instabilidade do comportamento, acompanhadas de dificuldade em atenção; violação de regras e pouco interesse nas tarefas. ${ }^{4-5}$ Sabe-se, porém, que essa indisciplina está agregada a contextos sociais, históricos, a valores, crenças e às políticas educativas dominantes, além do sistema pedagógico aplicado por professores e funcionários no ambiente escolar.

O desafio de educar no Brasil não é tarefa fácil, especialmente porque apesar da universalização do ingresso na escola permitir a expansão do ensino fundamental, tal evento não comportou sua equivalência no que tange à progressão da qualidade. 0 presente aumento da violência e segregação cultural coloca em perigo o pleno exercício da cidadania, evidenciada pela premência de uma nova concepção de educação escolar. ${ }^{6}$

Diante dessa perspectiva multidimensional torna-se evidente a necessidade em promover condições indispensáveis para operacionalização de medidas destinadas a conter e mesmo prevenir a violência na escola. Porém, estas são de extrema complexidade. Reforçar a importância de integrar ações que não se inclua somente a educação faz-se necessária. Fortalecer as ações no serviço de saúde com assistência psicológica, social, à lesão e legal, bem como organizações governamentais e não-governamentais ligadas ao contexto das práticas no cotidiano da escola constituem-se grandes ferramentas. 0 objetivo de construir e estruturar uma rede social que permita prestar melhor assistência aos adolescentes só pode ser alcançada com envolvimento de uma equipe inter e multidisciplinar. ${ }^{4}$

Ainda sobre a ação das instituições de ensino, cabe-se esclarecer que significa compreender que toda sua ação é tão importante que por vezes precede o próprio envolvimento dos alunos e familiares. Pois, tanto os alunos quanto seus familiares precisarão defrontar-se com a motivação da equipe para crerem nessa construção. ${ }^{7}$ 


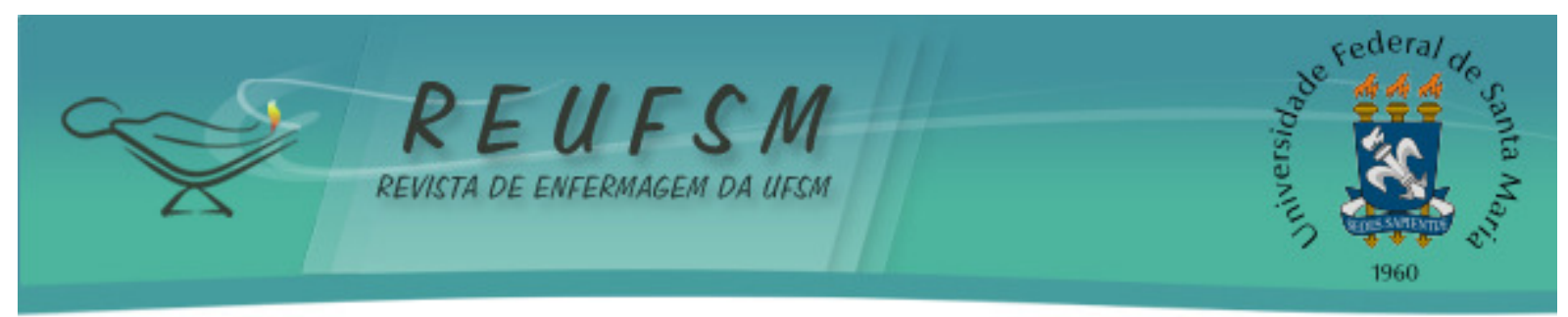

Nesse sentido, é essencial a articulação de professores e funcionários na criação e execução do projeto pedagógico, sendo possível assim, reproduzir uma nova realidade do ambiente escolar, com possibilidade de impacto favorável na população disposta no entorno da escola. A participação das mais distintas formações que faz com que, na sua singularidade, o funcionário note a relevância de seu cargo na manutenção da harmonia, ordem e disciplina na escola. ${ }^{8}$

Porém, neste setor, o da educação, a prevenção da violência escolar vem se configurando na ação e habilitação docente. É irrefragável a importância de ações na capacitação dos demais profissionais. Ainda que as incumbências executadas por este segmento, não sejam privativas da instituição pedagógica, tais como: merendeiras, secretários, auxiliares de limpeza, cozinheiras, inspetores, dentre outros, estas acabam por praticar uma função educativa junto aos estudantes. ${ }^{9}$

Portanto, é essencial discorrer que todos os profissionais da escola são protagonistas do sistema educacional e que podem juntos, contribuir para a criação e imposição de regra, tentando principalmente, coibir a indisciplina e buscar o controle do espaço escolar. ${ }^{6}$

Nesse cenário, como integrantes do processo educativo, os funcionários de uma forma geral tentam abolir os preconceitos enraizados culturalmente, que estão ancorados em uma visão de trabalhadores apenas braçais e alienados, inábeis para o desenvolvimento de funções pedagógicas.

Apesar da incontestável importância das ações dos funcionários na redução da transgressão de incivilidade dos adolescentes dentro do ambiente escolar, a literatura aponta intervenções apoiadas na atuação do professor. ${ }^{5}$

Assim, o objetivo dessa pesquisa foi conhecer as estratégias de contenção da violência escolar na visão de funcionários de uma escola estadual de ensino fundamental e médio do município de Divinópolis-MG. A entrevista foi conduzida pela questão norteadora: "O que você acha que pode ser feito para que não aconteça nenhum tipo de violência aqui na escola?".

\section{MÉTODO}

O presente estudo inscreve-se na linha de pesquisa descritiva de caráter qualitativo. Diante da natureza do objeto optou-se por desenvolver uma pesquisa que tem como delineamento pesquisa de campo $^{10}$, uma vez que não permite isolar e controlar as variáveis, mas perceber e estudar as relações estabelecidas. ${ }^{11}$

O estudo foi realizado no município localizado na macrorregião oeste de saúde do Estado de Minas Gerais. Compôs a população desta pesquisa dez funcionários de uma escola pública de ensino fundamental e médio, a maioria era do sexo feminino, com residência no bairro da instituição ou em bairros próximos; $50 \%$ trabalham no turno da manhã, $20 \%$ à tarde e $30 \%$ à noite. Predominou o vínculo empregatício único, com tempo médio de serviço de 13 anos. A escolha dos entrevistados ocorreu de forma aleatória, considerando a disponibilidade e interesse.

Foram elegíveis os funcionários que aceitaram participar da pesquisa e assinaram o termo de consentimento. Este trabalho foi aprovado pelo Comitê de Ética em Pesquisa do Hospital São João de Deus - Fundação Geraldo Corrêa sob Parecer №. 115/2011 e pelo Comitê de Ética em Pesquisa do Campus Centro-Oeste da UFSJ (CEPES/CCO) sob Parecer No. 016/2011.

A coleta de dados foi efetuada individualmente, na própria escola em horários previamente agendados, registradas em gravação de áudio, devidamente autorizadas pelos sujeitos da pesquisa. Uma vez identificada a semelhança no conteúdo dos relatos, constatou-se a saturação dos mesmos e optou-se para o término da coleta. ${ }^{12}$

Como técnica de análise de dados, os depoimentos dos entrevistados foram submetidos à análise de conteúdo. ${ }^{13} 0$ conteúdo das entrevistas foi organizado em uma ampla categoria temática: "estratégias para minimizar/prevenir a violência no ambiente escolar", sublinhando 


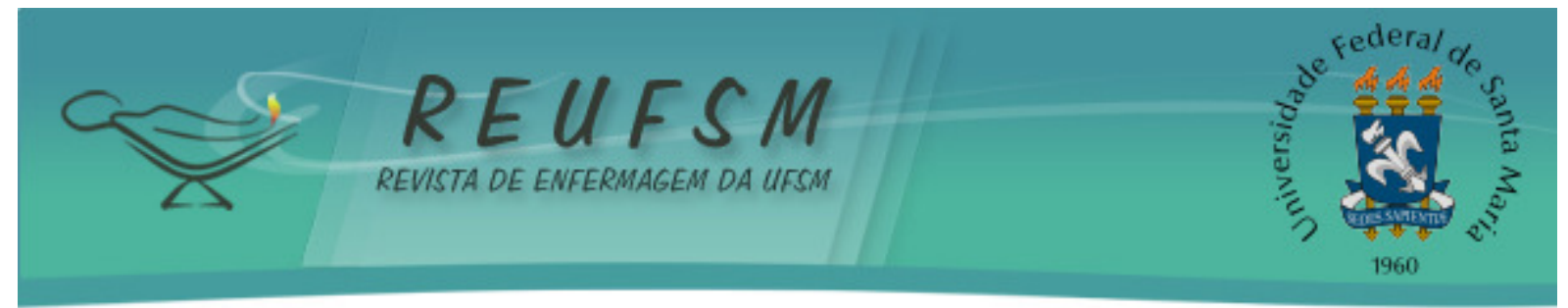

segmentos de texto, que permitiram a seleção de unidades de significação. A partir de discursos repetidos duas categorias foram organizadas: 0 papel da escola e 0 papel da família.

Para preservar o anonimato dos sujeitos da pesquisa, os mesmos foram identificados pela inicial "F" (funcionário), seguida de números naturais e em ordem crescente de acordo com a realização das entrevistas.

\section{RESULTADOS E DISCUSSÃO}

A partir da entrevista, os funcionários apresentam diversas sugestões do que pode ser feito para que não aconteça nenhum tipo de violência na escola. As estratégias de contenção da violência escolar na visão de funcionários de uma escola pública abrangem desde melhorias na educação familiar e formal, no relacionamento familiar e no contexto escolar ao estímulo à cultura da paz na escola. Nota-se que família e escola constituem o foco de ação na promoção da cultura da paz e na prevenção da violência escolar na perspectiva dos funcionários.

As marcas discursivas indicam que o grupo compartilha semelhantes opiniões quanto às estratégias para minimizar/prevenir a violência no ambiente escolar. Destaca-se a viabilidade de uma nova postura dos professores, com destaque no ensino de habilidades sociais, autocontrole e escuta; participação da psicologia no ambiente escolar na tentativa de auxiliar os alunos na elaboração de conflitos e a apreenderem a lidar com as dificuldades cotidianas; além da participação familiar na escola.

Apesar de o foco ser as medidas de contenção da violência no ambiente escolar, os funcionários também sinalizaram as possíveis gêneses deste cenário, destacando a agressividade como postura típica do adolescente. ${ }^{14}$ Porém, tal concepção detentora de a juventude ser um "problema social", é uma noção estigmatizante que se acirra por anos no imaginário social. ${ }^{15}$

Apesar de se compreender essa visão, uma vez que é retórica a participação dos alunos neste cenário, deve-se atentar que o desenvolvimento de tal comportamento ocorre durante sua formação recebida no lar e pela própria sociedade. ${ }^{16}$ Contudo, houve aqueles que não denegaram sua gênese social.

Sobre o envolvimento nesse cenário, além dos alunos, outros personagens foram mencionados, como professores e os próprios funcionários. A incompatibilidade de muitas variáveis entre alunos e professores/funcionários, é vista pelos entrevistados como fatores que influenciam diretamente no desempenho profissional e na produtividade dos adolescentes. Aquela postura histórica que outrora predominava, hoje é desprovida em sua representação social, e na tentativa de manter a ordem, o vocabulário adotado pelos alunos, por vezes, configura em um relacionamento desrespeitoso com gritos, agressões verbais ou, ocasionalmente físicas.

Neste contexto, os sujeitos da pesquisa pontuaram escola e família como instâncias socialmente responsáveis pela prevenção da violência escolar.

\section{O papel da escola}

Considerando a escola, observa-se que ela vem se configurando em um espaço de interações negativas, onde alunos, professores e funcionários se tratam com insultos, afronta e até mesmo, em alguns momentos, agressões físicas. Assim, a escola deixa de ser um ambiente em que as pessoas se capacitam para convivência participativa na vida social ${ }^{14}$, e uma formação que promova cidadãos críticos e conscientes.

Essa condição que vem se tornando corriqueira, permitiu a difusão da percepção dos funcionários em apreender medidas diversificadas de prevenção e redução da violência. No que tange as ações que envolvem professores, depoimentos relacionados à capacitação profissional são mencionados. 


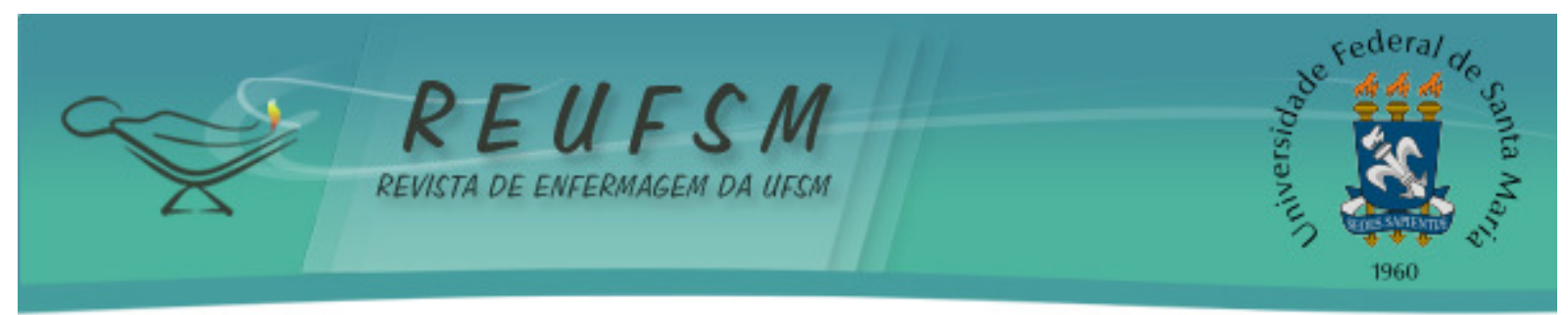

Porém, o treinamento deve buscar a qualificação ou aprimoramento de todos os profissionais do ambiente escolar no que se refere às habilidades de manejo das emoções, diante comportamentos violentos e antissociais dos adolescentes, com capacidade de intervir de forma competente, eficaz e efetiva. ${ }^{5}$ Assim, o que se espera é que diante situações de conflito, estes profissionais não apelem para estereótipos de forma pejorativa. ${ }^{14}$

Apesar de muitos entenderem que essas estratégias não são apoiadas pela literatura pedagógica, ainda sim, segundo relato dos entrevistados, há professores que possuem dificuldade em lidar com as situações de conflito, controlando a indisciplina com práticas inconsistentes.

[...] já presenciei aluno desacatando professor $e$ isso acontece de ambas partes. (F2)

[...] falta de tolerância, às vezes, do professor para com o aluno [...]. (F4)

Uma pesquisa revela que prevenir e reduzir a agressividade são tarefas complexas. As ações adotadas requerem intervenções nos períodos iniciais, principalmente, em escolas que possuem um elevado número de alunos com problemas de comportamento. Medidas gerais dirigidas a todos os alunos demonstram mais eficácia, pois quando aplicadas em estágios iniciais de padrão agressivo, a exposição sistemática dessa mediação pode ser suficiente para aconselhar e impedir um caminho negativo. ${ }^{5}$

É provável que as alternativas de punições demandadas pelas escolas estejam diversificadas, com ausência e/ou pouca equivalência direta com o tipo de ato efetuado pelos alunos, a ponto de provocar certa imprecisão. Banalizar, confundir os alunos e mesmo enfraquecer a validade da ação da escola acaba por contribuir para ocorrência dessa conduta. ${ }^{14}$

Ainda sobre o olhar dos funcionários quanto à conduta dos professores e alunos, há aqueles que ostentam certo inconformismo no caráter da aplicabilidade de regras e afirmam que a punição contribuiria para a prática pedagógica.

[...] falta de impor o respeito às vezes na própria sala e dentro do espaço escolar. (F2)

Punição. Eu acho que tem que ser punido tanto o aluno, quanto o professor que desacatar um aluno ou um aluno desacatando um professor, tem que ser punido. (F1)

À luz dos resultados encontrados, foi possível observar que em uma escola severa, onde as normas se baseiam fartamente na aplicação de punições categoricamente determinadas, pode colaborar em um local onde se cria formas ocultas de manifestação da agressividade. Refere-se ainda, que quando o diálogo e a prontidão da equipe escolar é vista como não requisito de respeito às regras, alguns alunos tendem a testar os limites daquilo que é aprovado e proibido, dispondo continuamente na situação de desafio. ${ }^{17}$

Abordando o fracasso pedagógico dos professores, é fácil compreendê-lo, pois o perfil agora delegado à escola se baseia em funções educativas, responsabilidades essas que a família contemporânea passou a transferir. Aliado ao fato, de que com a massificação da educação, grupos diversificados de alunos passaram a ter acesso à instituição de ensino e como a escola se organiza e forma professores preparando-os para lidar com alunos de formato e perfil modelo, acabam por enfrentar dificuldades na execução de práticas educativas. ${ }^{18}$ 


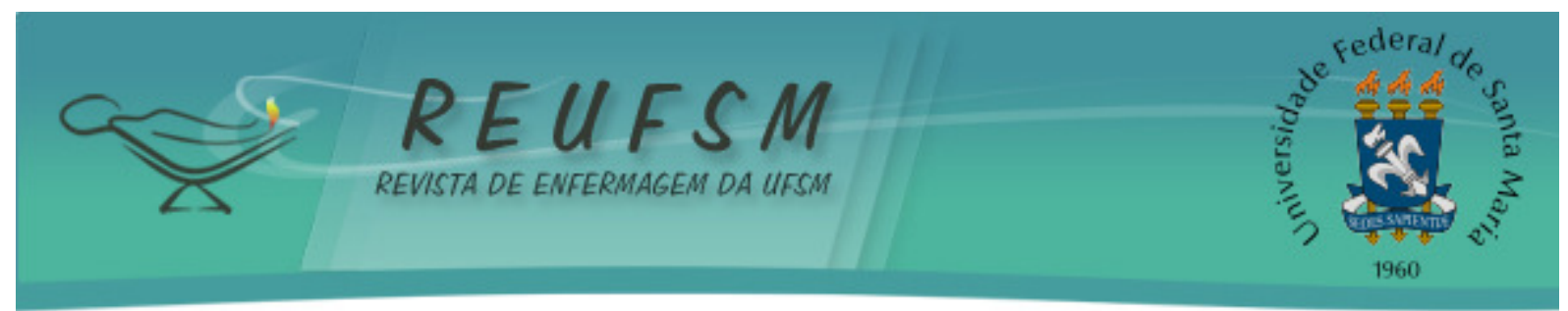

Quanto às estratégias que permitam interações sociais construtivas na relação alunoprofessor, os entrevistados proferiram também condições que contribuem para o exercício da cidadania dos jovens. Outros enfatizaram trabalhos, cujo foco seria os professores:

[...] um trabalho né?! Com os alunos, como reeducar [...] e ter assim, alguma coisa que chama a atenção dos alunos, por exemplo, cantar o hino nacional toda semana, alguma coisa que faça com que os alunos se reeduquem, tenha participação na escola e saiba calar, saiba falar na hora certa [...] apresentar um teatro, alguma coisa assim que possa integrar todos os alunos não só uma sala, mas toda a escola, integrar todas as salas. Eu gostaria que fizesse um trabalho com os alunos que tivessem aqui na escola é... uma psicopedagoga [...]. (F2)

Eu acho importante palestras, é... o professor trabalhar com eles estudos educativos, trabalhar com postura, dinâmicas, com novas metas, novas propostas e exposição mesmo dos fatos para que os alunos possam divulgar a real situação. (F4)

\section{[...] conversar, né?! É chegar e conversar, não chegar gritando. (F10)}

Eu acho que... muita preparação do professor, mais cursos de reciclagem né?! A parte de relacionamento humano, eu acho que falha muito. Palestras a respeito disso, seriam importantes[...]. (F1)

Considerando o exposto, pesquisadores confirmam que ações educativas que visem à formação para a cidadania contribuem de forma eficiente para formação ética dos alunos. ${ }^{19}$ Acredita-se que uma interação social construtiva reduz as chances de conflitos, tensões e mesmo na sua presença, o professor que for capaz de aproveitar todos momentos de interação, terá instrumentos para o controle.

Quanto às palestras, alguns autores discutem a importância de que o tema violência não deve ser somente trabalhado em palestras, o que faz necessário constituir o conteúdo programático a ser ministrado aos alunos. ${ }^{14}$ Para tanto, é essencial relevar que os professores tenham pleno entendimento dos referencias teórico e empírico que orientam as ações preventivas e de redução de comportamentos agressivos. ${ }^{5}$ Entretanto, propor tanto preparo aos professores requer cautela, é necessário recordar que o docente opera, muitas vezes, em condição oponente no que tange ao número de estudantes em sala de aula, recursos materiais e físicos, e que isso, por si só, evidencia um ambiente de violência em relação aos que ali se encontram. ${ }^{16}$

Quanto à formação dos professores, mencionada pelos entrevistados, é importante lembrar-se da já existente Rede Nacional de Formação Continuada de Professores (RENAFOR) ${ }^{20}$, programa cuja principal estratégia de ação é o financiamento de projetos de formação continuada de profissionais da rede pública de educação básica. Voltado para a promoção e a defesa dos direitos de crianças e adolescentes e enfrentamento/prevenção da violência escolar.

Essa estratégia, criada em 2004 pelo Ministério da Educação e a Secretaria de Educação Básica, surgiu como resposta à necessidade de articular a pesquisa, a produção acadêmica à formação dos educadores ${ }^{20}$, uma vez que a conclusão do ensino superior não norteia a constante qualidade prática do professor. Assim, a formação continuada permite contemplar a realidade e especificidades dos estudantes proporcionando um ambiente agradável por meio do comprometimento pedagógico. ${ }^{21}$ 


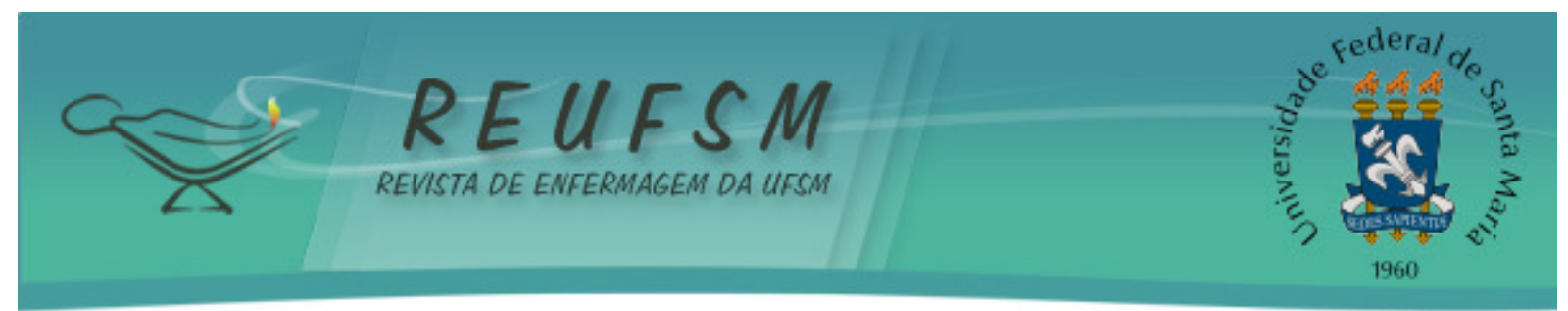

No âmbito social da educação escolar, a influência da Psicologia nas salas de aula também foi enfatizada. Como a situação é multiproblemática, deve-se reconhecer que ações multidisciplinares que aspiram ao desenvolvimento integral do estudante produzem chances destes se tornarem cidadãos produtivos. ${ }^{22} \mathrm{Um}$ estudo acrescenta ainda que 0 profissional psicólogo tem formação para aconselhar os professores quanto aos sinais da violência, o que permite desprender de ações preventivas e desenvolver programas que atente aos pais, uma vez que apesar de entenderem as estratégias, os professores não possuem formação específica para detectar e trabalhar com a violência. ${ }^{16}$

[...] Nós estamos com uma turma aqui que eu acho que professor não tá preparado para atendê-los. Acho que precisava de psicólogos, de psiquiatras. Nós temos vários casos que o professor não vai conseguir dar aula é nunca, que eles não estão preparados para esse tipo... não tem formação pra isso não. Então eu acho que precisava de um profissional aí nesta área de psicologia, para dar suporte [...]. (F1)

Acredita-se que o domínio destes contribuiriam em uma assessoria ao projeto pedagógico, averiguação de ferramentas de avaliação, além de explorar interações em sala de aula, fazer diagnóstico e referenciar problemas relacionados a queixas escolares. ${ }^{22}$

Os resultados do presente estudo se destacaram em termos de formação de professores. Quanto ao envolvimento dos funcionários, os mesmos não discorreram sobre instrumentos que pudessem abordar suas práticas no intuito de prevenir e/ou minimizar a violência, apesar de relatarem sua participação nesse cenário.

\section{[...] a gente tinha vontade que o aluno respeitasse mais o professor e o funcionário [...]. (F9)}

Como já discutido, reconhecer a importância do educador não docente ainda constitui um desafio. Esse reconhecimento requer primariamente que todos os espaços da escola sejam entendidos como espaços educativos tão importantes quanto a sala de aula. Implica em deixar que suas ações pedagógicas sejam alienadas, tornando funcionários conscientes de seu papel enquanto educadores e buscar a construção de uma nova identidade profissional, pra tanto, cabe sua profissionalização com formação inicial e continuada de acordo com os diferentes segmentos envolvidos. ${ }^{6}$ Espera-se que essa tentativa de ação por parte dos profissionais não seja incipiente quanto os avanços na legislação, sensibilização dos governantes, instrumentalização da escola e formação dos professores. Só com esse trabalho integrado serão desenvolvidas ações que auxiliem na identificação e na definição de como se operar/atuar diante situações de violência.

\section{O papel da família}

Quanto à relação entre pais e filhos, alguns indicadores de risco foram identificados pelos entrevistados. Geralmente esse núcleo é muito enfatizado, no entanto a abordagem dessa unidade funcional se restringiu. As concepções individuais reproduziam que o modelo de comportamento adotado no ambiente familiar valorizava a inexistência e/ou distanciamento do afeto e tal condição contribuía em um temperamento agressivo dos adolescentes, apontando à necessidade de criar estratégias para valorização do contato afetuoso dos membros da família, com ênfase na comunicação interpessoal: 


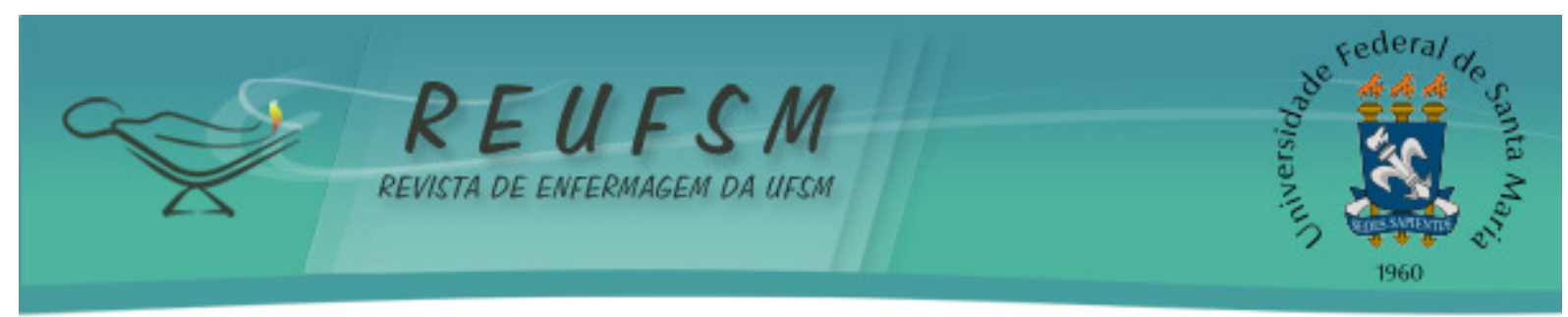

Dar muito amor, muito carinho, conversar mais [...] ter mais diálogo. (F8)

Assim, nota-se que a percepção da resiliência familiar para os entrevistados, só é alcançada quando se compartilha sentimentos com interações agradáveis, suprimindo a ausência das relações de apoio e evocando uma rede afetiva e social. A compreensão que vigora nas falas não se discerne dos achados da literatura, mostrando que os vínculos formados entre pais e filhos exercem papel fundamental na saúde mental durante a infância e a adolescência. ${ }^{23}$ Uma relação salutar do ponto de vista emocional serve como fator de proteção no que tange o desenvolvimento de psicopatologias. Mudanças na estrutura familiar, como famílias "monoparentais" ou desestruturadas, constituem em risco iminente para comportamentos negativos, geralmente expressos na escola com baixo rendimento e com características agressivas. ${ }^{4}$

Por vezes, é necessário compreender o contexto no qual os provedores das famílias viveram. As condições constituídas de auxilio material e afetivo, por exemplo, podem determinar o desempenho do futuro papel parental, com habilidades capacitantes ao cuidado e sustento dos filhos ou com dificuldades no engajamento emocional e na construção de um caráter disciplinar. ${ }^{24}$

Além do ambiente escolar e familiar mencionados pelos funcionários é importante identificar outras instâncias que se estruturam como parte dos fatores de risco no processo da educação. Investigadores envolvidos em estudos sobre a influência da violência escolar na aprendizagem dos alunos afirmam que as mensagens oriundas dos programas televisivos, como noticiários e desenhos ou mesmo o comportamento adotado por vizinhos e pais podem vir impactar e fazer com que os mesmos imitem parentes ou heróis da televisão, expressando suas emoções com provocações, ofensas, dentre outros. ${ }^{25}$

\section{CONCLUSÃO}

Apesar das fragilidades das políticas públicas em valorizar as habilidades acadêmicas e, principalmente, sociais dos professores, com raras ênfases na ausência de medidas de contenção por parte dos mesmos, começam a surgir possibilidades de intervenção sobre vários fatores aqui apresentados. Mesmo que restritas geograficamente e conscientes dos limites das ações pontuais, a estratégia de inserção da participação da comunidade no âmbito escolar além das capacitações dos profissionais envolvidos no processo educativo tem apresentado sinais de melhoria nas relações, com redução dos casos graves de violência no cenário escolar, perdurando ainda a violência que acontece de forma velada.

Oportuno ou não, o fato é que as narrativas dos entrevistados também não dispuseram da necessidade de implementar estratégias que os articulem na formação e capacitação requerida aos professores. Isso denota que, apesar da literatura contestar a importância do desenvolvimento de ações direcionadas ao profissional não docente, os mesmos não visaram sua protagonização como sujeitos requerentes de tal habilidade pedagógica. Por vezes pode-se pressupor que os mesmos possuem conhecimento de um número maior de situações de conflito entre professor-aluno, o que faz desses depoimentos condizentes com a real necessidade daquele ambiente.

Porém, como já discutido, o assunto violência possui uma perspectiva multidimensional de grande complexidade, portanto, discorrer de estratégias que visem somente à figura do professor não democratiza a comunidade educacional, tão pouco essa ação asseguraria uma instituição sólida isenta de problemas de comportamento. Assim, contesta-se que somente o desempenho pedagógico ruim de alguns 


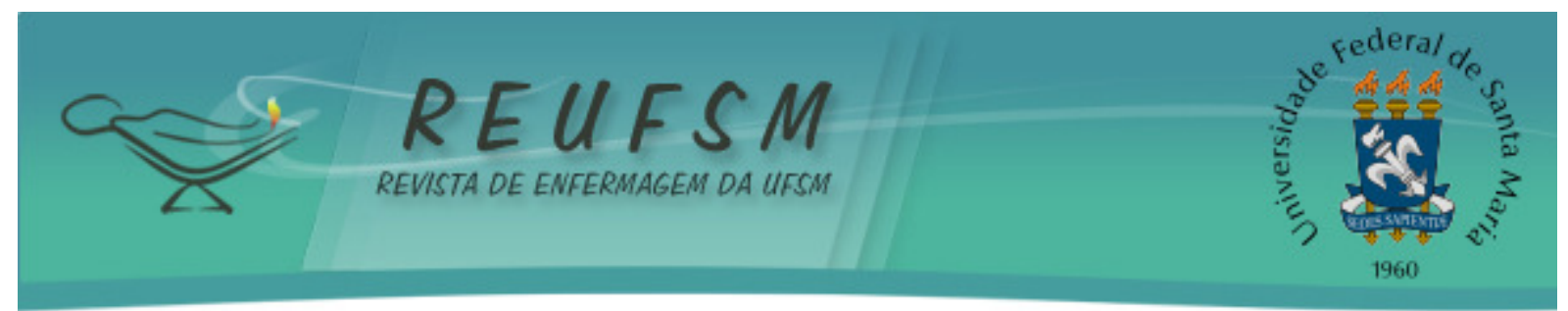

professores contribua para interações coercitivas com alunos, pois este, não constitui necessariamente o único e/ou principal problema estabelecido nesse ambiente.

Nesse ínterim, a práxis escolar deve visar também a análise de fatores intra e extraescolares que interferem nas ações pedagógicas. É fundamental compreender a necessidade da promoção da criança e do adolescente escolar junto à família; entender que a presença de outras categorias profissionais nas instituições de ensino ampliaria a discussão e os olhares dessa constatação árdua; que a concepção docente e não docente perpasse o alcance do saber, mas que conduza tais jovens a uma real cidadania; revisar o modelo da educação atual para condução de um sistema educacional focado em uma visão crítica da sociedade e por fim, que a prática pedagógica torne obsoleta a desigualdade social e preconceitos com uma educação democrática, disciplinada e de direito.

0 autêntico funcionamento em rede das escolas seria, portanto, o fator que colaboraria com a qualidade do ensino e também contribuiria para que esse espaço se torne um ambiente mantenedor da disciplina e da harmonia nas relações no interior da escola.

Enfim, estabelecer múltiplas parcerias com diversos setores e atores sociais constituem estratégias que devem ser levadas em consideração. Sobretudo a área da saúde, pois se compreende que a violência com sua magnitude e gravidade evoca melhores planejamentos de prevenção e promoção de saúde. Assim, à enfermagem, cabe o trabalho interdisciplinar, sendo apta na elaboração de estratégias que sejam eficazes no embarque do tema, com consequente desenvolvimento de atividades educativas orientando pais, escola e adolescentes para prevenção da violência no ambiente escolar.

\section{REFERÊNCIAS}

1. Schraiber LB, D’Oliveira AFPL, Couto MT. Violência e saúde: estudos científicos recentes. Rev Saúde Pública. 2006;40(N Esp):112-20.

2. Andrade EV, Bezerra Júnior B. Uma reflexão acerca da prevenção da violência a partir de um estudo sobre a agressividade humana. Ciênc Saúde Coletiva. 2009;14(2):445-53.

3. Ministério da Educação (BR). Secretaria de Educação Continuada, Alfabetização e Diversidade. Escola que protege: enfrentando a violência contra crianças e adolescentes. Brasília (DF): Ministério da Educação; 2008.

4. Netto Maia LLQG, Araújo A, Santos Júnior AS. Motivações para a violência no contexto escolar sob a óptica do adolescente. Rev Enferm UFSM [Internet]. 2012 jan/abr [acesso em 2013 jan 25];2(1):20-31. Disponível em: http://cascavel.ufsm.br/revistas/ojs2.2.2/index.php/reufsm/article/view/3760/3123.

5. Luizzi L, Rose TMS. Intervenções para a prevenção e redução de comportamentos agressivos e a formação de professores. Temas Psicol. 2010;18(1):57-69.

6. Ministério da Educação (BR). Secretaria de Educação Básica. Por uma política de valorização dos trabalhadores em educação: em cena, os funcionários de escola [Internet]. 2004 [acesso em 2012 ago 13]. Disponível em: http://portal.mec.gov.br/seb/arquivos/pdf/em_cena.pdf.

7. Eccheli SD. A motivação como prevenção da indisciplina. Educ Rev. 2008;32:199-213.

8. Longhi SRP, Bento KL. Projeto político-pedagógico: uma construção coletiva. Revista de divulgação técnico-científica do ICPG. 2006;3(9):1-26. 


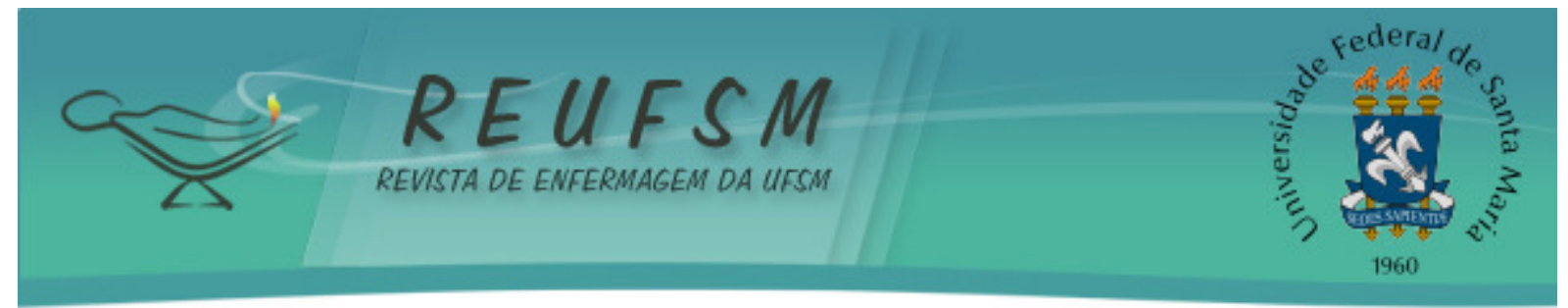

9. Trojan RM, Tavares TM. O funcionário escolar como educador: formação dos trabalhadores em educação da rede estadual de ensino. Em Extensão. 2007;6:58-70.

10. Günther H. Pesquisa qualitativa versus pesquisa quantitativa: esta é a questão? Psicol Teor Pesqui. 2006;22(2):201-10.

11. Rodrigues WC. Metodologia científica. Paracambi: FAETEC/IST; 2007.

12. Fontanella BJB, Luchesi BM, Saidel MGB, Ricas J, Turato ER, Melo DG. Amostragem em pesquisas qualitativas: proposta de procedimentos para constatar saturação teórica. Cad Saúde Pública. 2011;27(2):389-94.

13. Bardin L. Análise de conteúdo. $4^{a}$ ed. Lisboa: Edições 70; 2011. 280 p.

14. Abramovay M. Cotidiano das escolas: entre violências [Internet]. Brasília (DF): UNESCO. 2006 [acesso em 2013 jan 20]. Disponível em: http: / / unesdoc.unesco.org/images/0014/001452/145265por.pdf.

15. Oliveira MB, Rosa EM. Juventude, violência e alteridade. Temas Psicol. 2010;18(1):113-21.

16. Witter GP. Ponto de vista: violência e escola. Temas Psicol. 2010;18(1):11-5.

17. Silva RGD. Discutindo algumas faces do fracasso escolar como um "sintoma" da violência escolar: do individual à instituição. Educação: teoria e prática. 2011;21(36):84-100.

18. Chrispino A, Dusi MLHM. Uma proposta de modelagem de política pública para a redução da violência escolar e promoção da Cultura da Paz. Ensaio: avaliação políticas públicas em educação. 2008;16(61):597-624.

19. Marques FM. Conferência internacional "Educação, globalização e cidadania: novas perspectivas da Sociologia da Educação”. Rev Lusófona de Educação. 2008;11:185-6.

20. Ministério da Educação (BR). Secretaria de Educação Básica. Rede Nacional de Formação Continuada de Professores. Brasília (DF): Ministério da Educação; 2012.

21. Antunes HS, Ávila CC, Farias GF, Marchi TVB. Entre vivências e experiências na formação continuada de professores: as impressões do programa pró-letramento no Rio Grande do Sul. Teor Prát Educ. 2012;15(1):55-65.

22. Penteado TCZ, Guzzo RSL. Educação e psicologia: a construção de um projeto políticopedagógico emancipador. Psicol Soc. 2010;22(3):569-77.

23. Jordão $A B$, Ramires VRR. Vínculos afetivos de adolescentes borderlinee seus pais. Psicol Teor Pesqui. 2010;26(1):89-98.

24. Barzon MR, Mello ILMA, Bérgamo LPD, Faleiros JM. Negligência infantil: estudo comparativo do nível socioeconômico, estresse parental e apoio social. Temas Psicol. 2010;18(1):71-84.

25. CID HP, Díaz MA, Pérez MV, Torruella PM, Valderrama AM. Agresión y violencia en la escuela como factor de riesgo del aprendizaje escolar. Cienc Enferm. 2008;14(2):21-30.

Data de recebimento: 09/03/2013

Data de aceite: $23 / 08 / 2013$

Contato com autor responsável: Luciana Netto

E-mail: luciananetto@ufsj.edu.br

Endereço: Rua Sebastião Gonçalves Coelho, 400 sala 301.4 Bloco D - Chanadour, Divinópolis, MG, Brasil. CEP 35.501-296 